\section{Phasisches Ereignis}

Helga Peter

Marburg, Deutschland

\section{Englischer Begriff}

phasic event

\section{Definition}

Ein elektrophysiologisch registrierbares zerebrales, muskuläres oder autonomes Ereignis von episodischer bzw. zeitlich fluktuierender Art, das schlafabhängig auftritt. $\mathrm{Zu}$ den phasischen Ereignissen gehören beispielsweise die raschen Augenbewegungen im REM-Schlaf (auch phasisches REM genannt) oder kurze Muskelzuckungen (Twitches). Die Dauer der Einzelereignisse liegt typischerweise im Bereich von wenigen Millisekunden bis höchstens zwei Sekunden. 